\title{
THE CALORIMETRICAL ANALYSIS OF HYDRATED SALTS.
}

\author{
By F. G. DONNAN, Ph.D., aNd G. D. HOPE, Ph.D.
}

(A Paper read before the Faraday Society, Tucsday, November 30, I909, Mr. James Swinburne, F.R.S., President, in the Chair.)

\section{INTRODUCTION.}

Thomsen, in his Thermochemische Untersuchungen (vol. iii.), describes a long series of accurate investigations on the heats of solution of hydrated and partially dehydrated salts. His object in carrying out these measurements was the determination of the constitution of salt hydrates. The method consisted in subtracting from each other the values found for various states of hydration of the "salt" under investigation, and so endeavouring to find the total energy change per successive addition of one gram-molecule of water to the solid salt. It is unprofitable at the present time to enter into any detailed analysis of the methods pursued by Thomsen in the interpretation of his experimental results. It must suffice to say that, partly owing to a want of that light which our present-day knowledge of heterogeneous equilibrium gives us, and partly for other reasons, Thomsen's conclusions are in many cases quite erroneous, whilst in other cases his results do not lead him to any definite conclusion. Two examples will be sufficient to support this statement. In the case of sodium carbonate Thomsen deduces from his calorimetric data the existence of hydrated salts containing, respectively, I, 2, 5, 7, 8 , and ro molecules of water per molecule anhydrous salt."* It will be shown in this paper that when Thomsen's results are correctly interpreted they indicate quite clearly and definitely the existence of only three hydrated salts, namely, those with $I, 7$, and to molecules water per molecule anhydrous salt. And that these are the only stable hydrates which exist has been proved by the careful work of Wells and McAdam, jun. (Fourn. Amer. Chem. Soc., I907, 29, $72 \mathrm{r})$.

Again, in the case of the sulphates of the "vitriol" series, e.g., $\mathrm{ZnSO}_{4}, 7 \mathrm{H}_{2} \mathrm{O}$, \&c., Thomsen does not appear to arrive at any acceptable conclusions. It will be shown in the sequel that in the particular case of copper sulphate Thomsen's experimental results indicate with certainty only the existence of the penta- and mono-hydrates.

In obtaining his partially dehydrated salts, Thomsen caused the finely powdered highest hydrate to slowly dehydrate in a current of dry air at a relatively low temperature. As a method of successive dehydration this procedure is open to considerable objection, because, owing to the absence of equilibrium conditions, the question of the relative velocities of dehydration of the successive possible hydrates arises. We do not know, therefore, whether at any moment we have to deal only with two hydrates, i.e., two

* In the subsequent abbreviated edition of his researches (Systcmatische Durcltführung Thermochemischer Messungen, Stuttgart, 1906) Thomsen speaks much more guardedly concerning his results with sodium carbonate, but the interpretation is equally unsatisfactory. 
solid phases, as would be the case if equilibrium obtained, or whether there may not be present simultancously three or more solid phases. Should the latter alternative happen to be the true one, it is clear that no definite interpretation of the calorimetric data is possible. The only theoretically sound method would be to agitate the given partially dehydrated and finely powdered salt mixture in an enclosed evacuated pulveriser until equilibrium had been obtained.

It may be conceded, however, that Thomsen's procedure may approximate very closely to equilibrium conditions (i.e., successive dehydration and

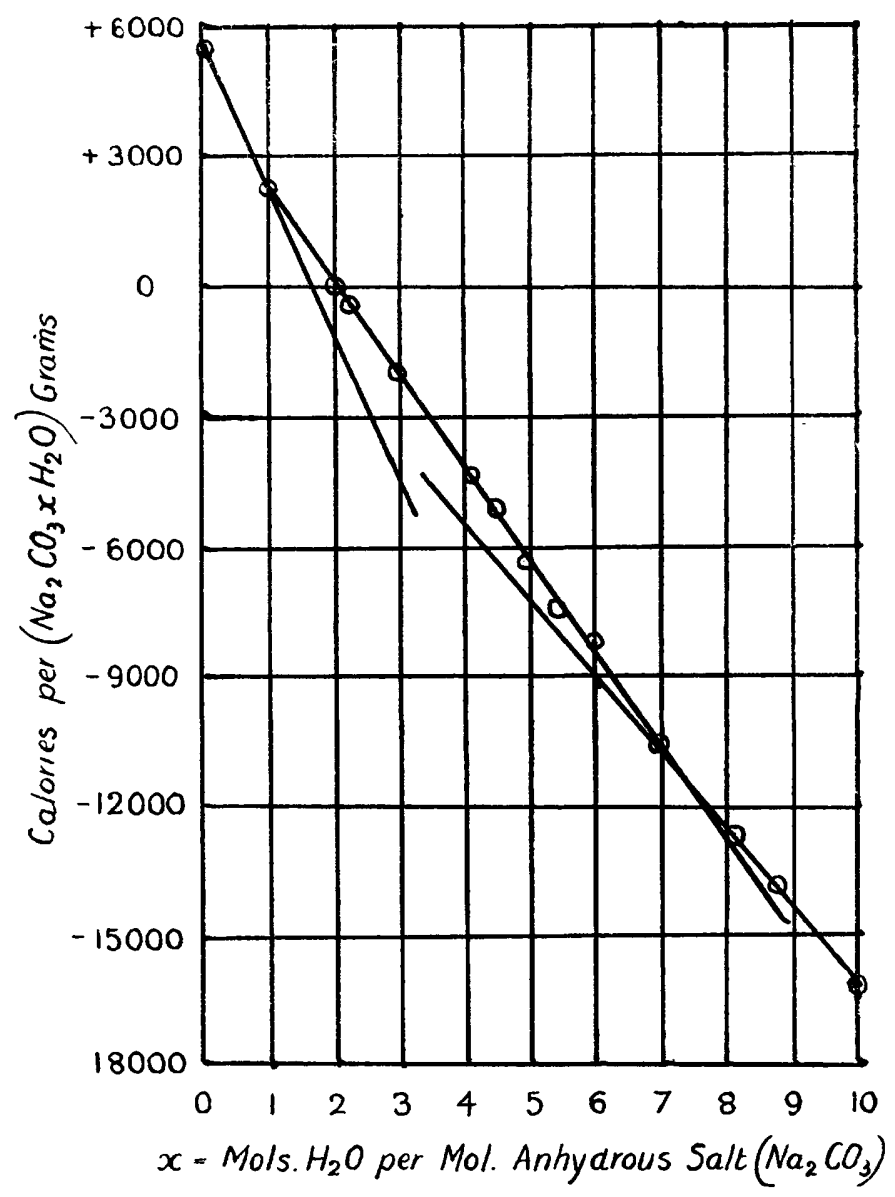

Fig. r.-Hydrates of $\mathrm{Na}_{2} \mathrm{CO}_{3}$ (Thomsen).

presence of only two solid phases) when the process of dehydration is sufficiently slow and the salt mixture continually repulverised.

Granting then that under favourable conditions we have to deal in any given mixture with two successive hydrates, we may proceed as follows. Taking the case of sodium carbonate for example, and denoting the average composition by the formula $\mathrm{Na}_{2} \mathrm{CO}_{3} \cdot x \mathrm{H}_{2} \mathrm{O}$, we have-

$$
\mathrm{Na}_{2} \mathrm{CO}_{3} \cdot v \mathrm{H}_{2} \mathrm{O}=p\left(\mathrm{Na}_{2} \mathrm{CO}_{3} \cdot m \mathrm{H}_{2} \mathrm{O}\right)+q\left(\mathrm{Na}_{2} \mathrm{CO}_{3} \cdot n \mathrm{H}_{2} \mathrm{O}\right),
$$


where $m$ and $n$ denote the mols. water present per mol. $\mathrm{Na}_{2} \mathrm{CO}_{3}$ in the two co-existent hydrates. From the above equation we get $p=\frac{x-n}{m-n}$, $q=\frac{m-x}{m-n}$, where $m>x>n$.

Let the heats of solution (in dilute solution) of the hydrates $m$ and $n$ be

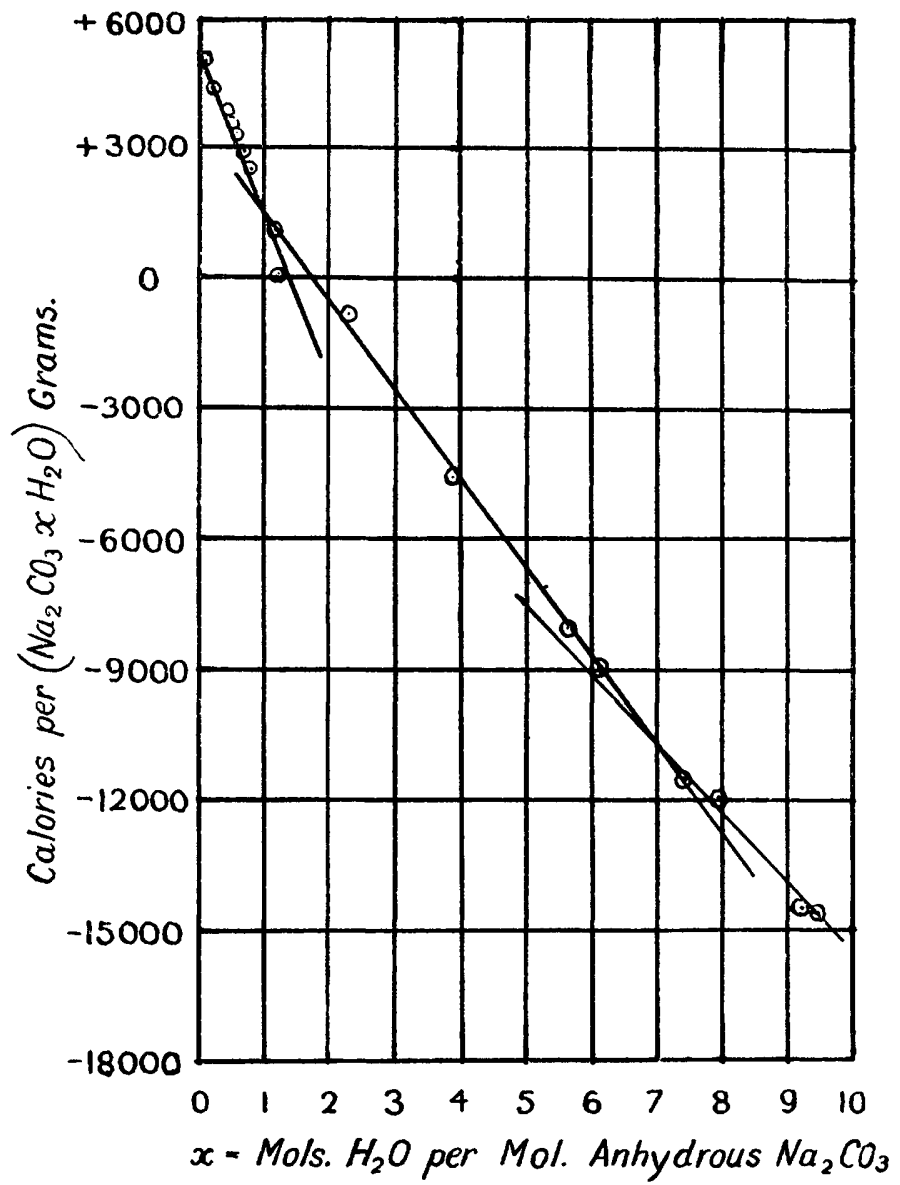

Fig. 2.-Hydrates of $\mathrm{Na}_{2} \mathrm{CO}_{3}$ (Donnan and Hope).

$a$ and $b$ calories respectively per gram formula weight. Then the heat of solution $y$ of the mixture $\mathrm{Na}_{2} \mathrm{CO}_{3}, x \mathrm{H}_{2} \mathrm{O}$ per gram formula weight will be given by the equation-

$$
y=a \frac{x-n}{m-n}+b \frac{m-x}{m-n} .
$$

Thus if we plot $y$ as a function of $x$ each pair of successive hydrates will determine a particular straight line, so that the result will be a series of straight lines intersecting at the values of $x$ corresponding to the successive definite hydrates. 
It may be here remarked that, apart from the other factors discussed above, the validity of this method of procedure depends on the assumption that the heat of solution of a mechanical mixture of two definite hydrates is equal to the sum of the heats of solution of the same quantities of the two hydrates determined separately. This assumption will doubtless hold good with sufficient approximation provided the heats of solution in sufficiently dilute solution are measured. Should any of the successive hydrates form molecularly homogeneous mixtures giving monophase systems, the $y=\phi(x)$ linear complex will transform partially or completely into a continuous curve. It is probable, however, that this case is not very common.

\section{EXPERIMENTAL.}

As an illustration of the application of the principles discussed in the preceding section, Thomsen's measurements for sodium carbonate and cupric sulphate have been plotted in the manner described, and as Thomsen's data are rather scanty for the mixtures of anhydrous salt and lowest hydrate in each case, redeterminations of the heats of solution have been carried out. For this purpose the very finely pulverised saits were allowed to slowly dehydrate over sulphuric acid at room temperature. The dehydrating salt mixture was frequently repulverised, and whenever a sample was taken for the calorimetric determination a corresponding sample was simultaneously taken for analysis. The calorimetric determinations were made in an ordinary calorimeter with air space and water jacket, the inner calorimeter vessel consisting of gold-plated silver and holding about 500 c.c. The finely powdered salt enclosed in a stoppered weighing bottle and the calorimeter were allowed to remain in a basement room of fairly constant temperature for about twelve hours before a determination was begun, so as to reduce the initial radiation correction to a minimum. The remainder of the experiment was carried out in the usual manner. It is not pretended that the values obtained compare in accuracy with the determinations of Thomsen. It is sufficient for the present purpose that they are comparable amongst themselves. Table I. contains Thomsen's experimental results for sodium carbonate. The end-concentrations correspond to I mol. of anhydrous salt per 400 mols. water.

TABle I. (Thomsen's Data).

\begin{tabular}{|c|c|}
\hline$x$ & $\begin{array}{l}y=\text { Heat of Solution in Calorics } \\
\text { per } \mathrm{Na}_{2} \mathrm{CO}_{3} . . x \mathrm{H}_{2} \mathrm{O} \text { grams. }\end{array}$ \\
\hline $\begin{array}{l}\text { o } \\
\text { I } \\
2 \cdot 007 \\
2 \cdot 234 \\
2 \cdot 280 \\
2 \cdot 965 \\
4 \cdot 062 \\
4 \cdot 430 \\
4 \cdot 889 \\
5 \cdot 397 \\
5 \cdot 956 \\
6 \cdot 955 \\
8 \cdot 048 \\
8 \cdot 745 \\
10 \cdot 000\end{array}$ & $\begin{array}{rr}+ & 5,636 \\
+ & 2,254 \\
+ & 12 \\
-\quad 436 \\
-\quad 589 \\
-\quad 1,980 \\
=\quad 4,363 \\
=\quad 5,065 \\
=\quad 6,380 \\
=\quad 7,490 \\
=\quad 8,294 \\
-10,670 \\
-12,725 \\
-13,937 \\
-16,161\end{array}$ \\
\hline
\end{tabular}


Plotting $y$ against $x$ we get Fig. $\mathrm{I}$, which clearly consists of three straight lines intersecting at two points corresponding to $x=\mathrm{I}$ and $x=7$. In Fig. 2 are plotted the values as redetermined by us. Here the position of the straight line corresponding to mixtures of $\mathrm{Na}_{2} \mathrm{CO}_{3}$ and $\mathrm{Na}_{2} \mathrm{CO}_{3}, \mathrm{H}_{2} \mathrm{O}$ is fixed by a large number of determinations.

It follows clearly from Figs. I and 2 that the only definite hydrates (besides the decahydrate) whose existence can be definitely detected in this manner are the well-known monohydrate and the less well-known heptaliydrate. There is no indication of the other hydrates mentioned by Thomsen.

As mentioned before, this result agrees with the solubility and thermometric data obtained by Wells and McAdam, jun. Thomsen mentions in his original work that he obtained a dehydrate by crystallisation from solutions of sodium carbonate, but this result would appear doubtful.

Table II. contains the calorimetric data on which Fis. 2 is based.

TABLE II.

\begin{tabular}{c|c}
\hline$x$ & $\begin{array}{c}y=\text { Heat of Solution } \\
\mathrm{Na}_{2} \mathrm{CO}_{3} \cdot x \mathrm{H}_{2} \mathrm{O} \text { grams. }\end{array}$ \\
\hline $0 \cdot 057$ & $+5,020$ \\
$0 \cdot 221$ & $+4,440$ \\
$0 \cdot 449$ & $+3,880$ \\
$0 \cdot 480$ & $+3,660$ \\
$0 \cdot 547$ & $+3,540$ \\
$0 \cdot 570$ & $+3,350$ \\
$0 \cdot 672$ & $+2,930$ \\
$0 \cdot 769$ & $+2,570$ \\
$1 \cdot 174$ & $+1,140$ \\
$2 \cdot 305$ & -820 \\
$3 \cdot 882$ & $-4,590$ \\
$5 \cdot 677$ & $-8,050$ \\
$6 \cdot 093$ & $-8,970$ \\
$7 \cdot 422$ & $-11,500$ \\
$7 \cdot 956$ & $-12,000$ \\
$9 \cdot 222$ & $-14,500$ \\
$9 \cdot 434$ & $-14,600$ \\
\hline
\end{tabular}

In Table III. are given the heats of solution of $\mathrm{CuSO}_{4} \cdot x \cdot \mathrm{H}_{2} \mathrm{O}$ as determined by Thomsen, and in Table IV. the values as determined by ourselves.

TABLE III. (Thomsen's Data).

\begin{tabular}{l|c}
\hline$x$ & $\begin{array}{c}y=\text { Heat of Solution } \\
\text { per } \mathrm{CuSO}_{+}, x \mathrm{H}_{2} \mathrm{O} \text { grams. }\end{array}$ \\
\hline 0 & $+15,820$ \\
1.03 & $+9,229$ \\
2.227 & $+5,425$ \\
3.315 & $+2,123$ \\
4.167 & +65 \\
5.000 & $-2,750$ \\
\hline
\end{tabular}


TABLE IV.

\begin{tabular}{c|c}
\hline$x$ & $\begin{array}{c}y=\text { Heat of Solution } \\
\text { per CuSO } \mathrm{O}_{4} \cdot x \mathrm{H}_{2} \mathrm{O} \text { grams. }\end{array}$ \\
\hline 0.067 & $+15,100$ \\
0.126 & $+14,807$ \\
0.190 & $+14,300$ \\
0.274 & $+13,500$ \\
0.345 & $+13,300$ \\
0.393 & $+13,100$ \\
0.641 & $+11,600$ \\
0.810 & $+11,000$ \\
$1 \cdot 418$ & $+9,510$ \\
$1 \cdot 730$ & $+7,840$ \\
1.777 & $+7,910$ \\
$2 \cdot 852$ & $+3,720$ \\
3.799 & +570 \\
4.253 & -660 \\
4.366 & $-1,020$ \\
4.533 & $-1,860$ \\
4.811 & $-2,600$ \\
\hline
\end{tabular}

Fig. 3 shows the result of plotting the data given in Table IV., the experimentally determined points being shown by small circles. The combined small squares and crosses correspond to Thomsen's data as given in Table III.

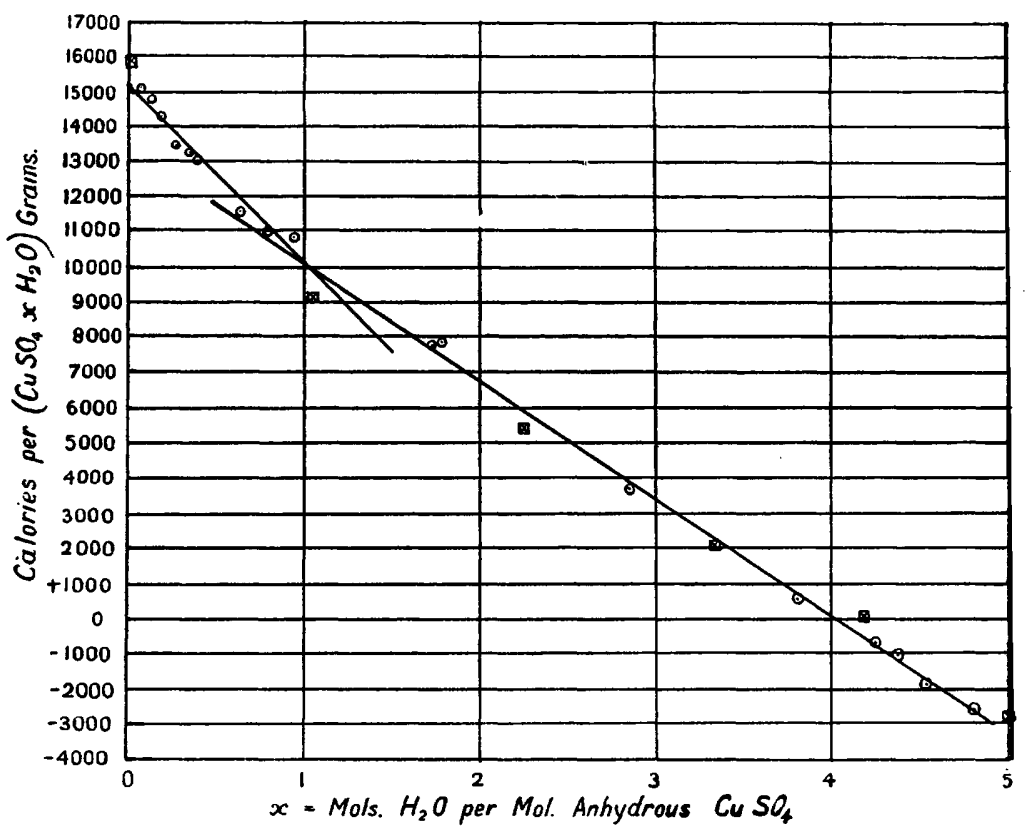

FIG. 3.-Hydrates of $\mathrm{CuSO}_{4}$.

The results are not so regular in this case as in that of sodium carbonate, and the calorimetric data do not indicate with certainty any lower hydrate other than the monohydrate. It may appear curious that the trihydrate, 
whose existence is certain, is not indicated by a "break," but this is probably due to the fact that the break will be clearly a very slight one (since the angle between the lines at the monohydrate break-point is already very small), and the calorimetric data are neither sufficiently numerous nor exact to indicate it. It is, of course, just possible that in the dehydration the trihydrate is really passed over, or that the velocity of dehydration of the tri- to the monohydrate is much greater than that of the penta- to the tri-hydrate.

\section{Summary of Results.}

I. It has. been shown that calorimetric measurements of the heats of solution in dilute solution of partially dehydrated salt mixtures may be employed as an aid in the discovery of the existence of definite hydrates, although owing to the difficulty of making accurate determinations of the heats of solution this method is not so reliable or convenient as the other well-known methods.

2. It has been shown that in certain cases, of which that of sodium carbonate is a striking example, Thomsen drew conclusions from his calorimetric data which cannot be regarded as justified by these data, and which are in disaccord with other experimental evidence.

Muspratt Laboratory of Physical and Electro-Chemistry,

UNIVERSITY OF LIVERPOOL, November I, I909. 